\title{
A CONDITIONAL ANALYSIS OF MOVERS' IOUSING RESPONSES
}

\author{
James N. MORGAN \\ Institute for Social Research, University of Michigan, Ann Arbor, MI 48106-1248, USA
}

Received February 1989, final version received March 1990

\begin{abstract}
Movers' responses to the five-year trend in income prior to the move are studied using data from the Panel Study of Income Dynamics and the new Slopes-Only option in the Search program in OSIRIS. Other events around the time of the move mask or dominate the income effects, and even for otherwise stable families there are subgroup differences in the income elasticities. Modelling housing demand clearly requires such rich response data imbedded in dynamic simulation models.
\end{abstract}

\section{Guy Orcutt's contributions to the empirical data base for economic analysis}

Guy Orcutt's interest in simulation drove him earlier than most, and in more realistic ways, to a realization of the need for better data. It also affected the kinds of analysis for which the data were used, for the simple reason that estimating subsequent changes from initial states does not require solving all the problems of simultaneity. Joint decisions can be treated as sequential, conditional decisions with no loss of predictive untangling all the causal relations.

In practice, this meant that Guy supported the initiation of the Panel Study of Income Dynamics (PSID) and, more crucially, supported and through the Urban Institute provided the crucial interim funds for continuation of the full sample of the PSID, not just the low-income segment.

One of his first suggestions as a member of the Board of Overseers of the Panel Study after it became a National Science Foundation operation was to point to the need for adding to the data file more information about the local environment, including not just county or census tract income and education and employment, but also fresh data not easily available, such as pollution of the air and water. We are currently adding Census tract identifiers with special safeguards, though we have always collected county data on unemployment and unskilled wage rates, and made official county data available.

Guy is one of a small group of excellent economists who started out in macroeconomics and econometrics but then concluded that the information in macrodata is soon exhausted, and that the easily available microdata collected for other purposes was inadequate. At the same time, he did not 
insist on the precision necessary for 'testing' complex models, nor blame failures to fit theoretical models on inadequacies of the data. Along with Leo Hurwicz, he pointed out early that errors in explanatory variables, overlooked in macro models, played hob with attempts to assess the relative strength of competing variables, representing alternative hypotheses.

At one point he and I hoped to create a symbiotic operation. The Survey Research Center would focus on data collection and estimation of relations; the Urban Institute would build simulation models, and perform sensitivity analyses to identify the relationships most in need of tighter specification and estimation. Inadequate and short-horizon funding and an insistence on fast answers to immediate policy problems and perhaps the sheer magnitude of the task of estimating all the necessary initial-state-subsequent-change relations, have left the whole important area of simulation far short of its promise. This has also affected the way in which behavioral data have been collected. Not only have we failed to focus on the kinds of data useful for simulation, but there has been no feedback from sensitivity analysis of simulation models to focus data collection on estimating the effects of variables with the greatest effects on outcomes in dynamic systems.

One development is, however, in the mill which may prove useful. It is the addition to the SEARCH computer program which properly focuses a covariance search on differences in the effects of $X$ on $Y$. The present 'regression' option results in divisions of the sample dominated by differences in $Y$, since shifting the level of a regression line has more effect on variance than shifting its slope. The new 'slopes only' option requires more effect on variance than shifting its slope. The new 'slopes only' option requires recentering each subgroup to avoid distortions. Even using the regression option it is possible to show that for some subgroups (well-educated professionals) there is a negative correlation between hours of work and health (shades of stress and the immune system), and that the effects of prior income trend on upgrading of housing among movers is substantially greater when there are also changes in the family. Clearly, models which attempted to use a single income elasticity of the demand for housing would be flawed.

In the long run, it will surely turn out that Guy was prophetic and right. If we are to use the rich information about individual behavior to derive implications for outcomes in complex dynamic systems, we must somehow deal with the aggregation problem. We may learn something from fractal geometry, but ultimately rich outputs will require rich inputs.

\section{An analysis of panel data}

We present here some substantive results which also illustrate underutilized aspects of the data from the Panel Study of Income Dynamics, some of the powerful recode capabilities of the OSIRIS software distributed by our 
Institute for Social Research, and a new 'slopes-only' option in the SEARCH program in OSIRIS. The substantive issue is important because the future of housing lies in upgrading by movers, not in the ever smaller number of new families being formed. The importance of the new 'slopes-only' option lies in the fact that economic theory deals with marginal choices, but many people are not at the margin. Testing and cstimating cconomic effects requires locating those at the margin with real choices to make. Furthermore, the power of behavioral findings is greatest when we can specify for whom and under what circumstances something we can predict or alter by policy will affect something else we think important.

Panel data allow us to answer such questions in a dynamic model with fewer assumptions, and also to test for lags. Persistent interpersonal differences mostly disappear when we examine change over time. Lags in response are likely to be larger for changes in housing than for changes in food consumption, and lags in the effect of income changes are likely to be slower than lags in response to changes in family size. Cross-section data reveal mostly long-term effects, since most people in any income group have been there for a while.

Housing can be adapted to changes in need for space or in ability to pay only sporadically, and mostly by a costly process of moving. A full behavioral model would first account for the decision to move, combining a variety of factors including moves forced by job changes, fire, loss of tenancy, or induced by changes in income or family size. Jointly or separately, the decision to change tenure (become an owner) could be considered separately from upgrading. And one might want to examine the lags, to sce whether adjustments to changes in family size (which might sometimes be endogenous or jointly determined) come faster than adjustments to changes in income or wealth.

We prefer to ask a hopefully easier question - given a decision to move, for whom does prior change in income or needs for space have the most effect? There are dangers in such an approach. Younger, more affluent people, or those with more education, might move more frequently, with less incentives from changes in income or family size, so it would look like such changes had less effect on the increase in their housing costs. A full simulation of the effects of economic or demographic changes would have to include both the effects on the probabilities of moving, and on the extent of change in housing costs for the movers, dealing, in other words, with possible selection bias.

One might also want to assess the lags - how long it takes before changes in the environment or the family have their effects. However, lags should mostly affect whether the family moves, though once a family moves, the more distant the prior changes in income or family size, the more likely the family has already adjusted to them by moving earlier, or by habituation. 


\section{Related research}

There are good summaries of research on housing supply, demand, and markets in Smith (1988), de Leeuw (1971), Mayo (1981) and Quigley (1979). And there are two good criticisms pointing out difficulties with attempts to estimate hedonic price models in Murray (1983) and Brown and Rosen (1982). There is a Census monograph on housing [White (1987)]. And at least two books report on housing allowance experiments, which get at the income and price elasticity of housing [see Downs and Bradbury (1981) and Friedman and Weinberg (1982)].

There have also been articles on the investment aspects of housing, and the possibility of imbedding housing demand in a full model of portfolio choice [see Henderson (1985), Rothenberg (1983) and Ioannides (1989)]. There studies of moving and tenure choice [see Henderson and Ioannides (1983, 1986, 1987) and loannides (1987)]. And there have been studies using the Panel Study of Income Dynamics (PSID) relating initial dissatisfaction with the community and house, or departures from expected space requirements, to subsequent moves [see Newman and Duncan (1978) and Goodman (1976)]. Most recently, the PSID has been used in a sophisticated model combining decisions about tenure, length of stay (expected) and housing consumption level [Henderson and Ioannides (1989)]. In contrast, we search for interpersonal differences in the upgrading response to prior income trends, conditional upon a decision to move, and merely accounting for tenure changes.

\section{Searching for structure}

Guy Orcott once suggested that we don't appreciate how the physical sciences focus on a single explanatory variable that can be manipulated or predicted, and ask under what circumstances it appears to affect something else in which we are interested. In that way they learn how to control a lot of things, even if they don't always understand why it works.

The implication is that in analyzing observational data such as those from surveys or panels, we ought to be doing less of the usual modelling and more covariance analysis where the covariate is something interesting like wage rate, or family size, or family income or availability of employment, and the dependent variable is work hours, or consumption of housing, or saving. Given the well-known dangers of inferring dynamic behavior from static cross-section data, clearly panel data would be optimal.

As a tentative response to this suggestion, we have managed to revise the 'slopes-only' feature of the covariance-search option in a computer program originally called the Automatic Interaction Detector (AID) and now called SEARCH. It searches systematically with a pre-stated and reproducible 
strategy. With a simple dependent variable, it searches sequentially for subgroups the splitting off of which maximize the explained variance, i.e. which are widely different on the criterion variable but also both large. The new covariance option looks for subgroups that differ in the relation of $X$ to $Y$, but since a difference in level of $Y$ is far more powerful than a difference in the regression slope, a special option eliminatcs that by recentering, in a search for subgroups where the regression slopes are different.

One can use this program with static data. For example, if one asks where gender affects wage rates, the program will show that among young people, there are very small gender differences, but they appear later in life, presumably as a result of differential (discriminatory) promotions, or women losing experience by dropping out to have children.

But other $X$ variables appeal when we have panel data, some of them also dichotomies, such as changing jobs or moving, others measurable such as changes in hourly earnings or in family size or income. It does not matter for now whether these are totally exogenous, or mainly a matter of individual choice, or some mixture, so long as there is no serious issue of reverse causation. Indeed, one of the things we might look for as explanatory classification variables, are things which restrict or enlarge people's options. The effect of any one $X$ variable may well depend on whether there are other constraints or pressures that dominate, so that those individuals are not at the margin where $X$ can work. It may well be that we can show that our economic theories of behavior work, but only for the unconstrained (marginal) people. This would explain why many analysis results from survey rescarch have been so unsatisfying.

At any rate, it seems useful to present some results of a search for population groups which differ as to the effects of the five-year prior income trend on movers' change in house values. We take the change in house value from a year ago, before the move took place, minimizing the inflation effects, and do not deflate the income or house value variables since it is interpersonal differences we seek, rather than an unbiased estimate of the marginal propensity to spend income increases on housing.

Some people rent, and some neither own nor rent. We make a rough conversion by multiplying the annual rent, or rent-equivalent estimated by respondents who neither own nor rent, by 10 . (Respondents who neither owned nor rented were asked what their residence would rent for.) Those who switch into or out of owning, however, often make substantial changes in real housing costs (abundant evidence exists that people are willing to pay more to own a house than they would pay to rent the same house). Hence, we take account of changes to and from ownership coincident with the move by adding appropriate categorical predictors.

Indeed, as we shall soon see, we have a mixture of effects from the past and from initial situations, with the effects of other changes taking place at 
the same time as the move. Once again, we are attempting to deal with a part of a larger problem which includes a set of joint decisions about changes in family, residence, and jobs.

We use the means option in SEARCH to analyze change in house size (rooms), since as it turns out, income change is not an important factor therc. With change in house value, we present both the regression option which seeks to separate groups with widely different simple regressions of five-year income path on change in number of in house value, and the new 'slopes-only' option which recenters all groups and isolates those with different effects of income trend on housing upgrading. (Housing costs and hence consumption are a reasonably linear function of house value.) The groups which result from the regression option maximize the variance accounted for by both the mean change in rooms or house value and the effects of income change on that change. Of course, a difference in the mean of $Y$ will do much more to reduce unexplained variance than a difference in the regression slope on income change. Since the slopes option is so new, we present some results for both it and the regression option for comparison.

The data are from the Panel Study of Income Dynamics, using the 1984 multi-year family tape. We combine all cases who moved in any of the five years 1978-1983, shifting the explanatory variables so they are relative to the year of the move. (This is easy with the Recode in the OSIRIS software.) But in any year, some families have a new head, because a single woman got married, a former wife divorced or became widowed, or because a child left home to form a new household. Changes in income become difficult to interpret in these cases, and housing decisions are clcarly dominated by changes in the family. Hence in examining change in house size, we force the search process first to make two splits forming three groups: families with the same head as the previous year, those with a wife who became head, and others with a different head from the previous year (single women who married, children who left home to form their own households). And when we turn to change in house value, we select only moves where the family has had the same head for the prior FIVE years, only 2,887 out of the 8,120 moves over the five years $(1978-1979 ; 1982-1983)$. In the case of house value the dependent variable is the difference in house value divided by the mean of the two values (to avoid scale-effects). The covariate is the five year trend in family money income divided by the five year mean, i.e., the slope of the trend in income relative to its level.

\section{Variables and methods}

To justify the use of a difference divided by the sum (or mean) notice the nice symmetry it produces for changes in both directions: 


\begin{tabular}{llccc}
\hline $\begin{array}{l}\text { Initial house } \\
\text { value }(\$)\end{array}$ & $\begin{array}{l}\text { Final house } \\
\text { value }(\$)\end{array}$ & Ratio & \% change & $\begin{array}{l}\text { Diff./ } \\
\text { average }\end{array}$ \\
\hline 100,000 & 300,000 & 3.0 & 200 & 1.00 \\
100,000 & 200,000 & 2.0 & 100 & 0.67 \\
100,000 & 100,000 & 1.0 & 0 & 0.00 \\
100,000 & 50,000 & 0.50 & -50 & -0.67 \\
100,000 & 33,333 & 0.33 & -67 & -1.00 \\
\hline
\end{tabular}

So averaging two people one of whose house value doubled and one of whose house fell to half, would give an appropriate average of 0 rather than the $+25 \%$ average ratio.

We introduce the following categorical 'predictors' in all the analyses, allowing the SEARCH routine to divide the sample at any point down the rank order that would do the most good. (Numerical variables were put into categories, losing almost none of their potential power.)

\section{Temporally prior variables}

1. Trend in family income over the five years prior to the move, divided by the five-year average income. Trend is the regression on time, simple to compute because time has values $-2,-1,0,1$ and 2 . We reran the regression and slopes-only analyses using the time-trend in family income relative to needs over the five years prior to the move. This is a better measure of increasing level of ability to pay for housing, and minimizes the distortions from the few families that changed composition in the five years before the year of the move. But we do not present those analyses because the results in terms of what matters were similar, and less easy to interpret.

2. Actual minus required rooms just before the move, a measure of pressure for more space. ('Required' specifies that two different gender children can share bedrooms until they are 10 years old, and same-gender children until they are 18. It assumes a requirement of 2 rooms for the head, with or without a wife, one more for each additional married couple or single adult 18 or over, for each two single boys or two single girls $10-18$, and for each two children under 10.)

3. Change in required number of rooms in five years ending after move, as a measure of longer-term pressure building up.

4. Change in actual number of rooms in five years ending before move, as a measure of prior housing adjustments. (Perhaps we should have replaced these last two with the change in actual-required rooms.) 
5. Change in whether a wife in the unit, a proxy for marriage or divorce, and for family cohesion and interest in the home. We use five groups: got married, stayed married, stayed single man, stayed single woman, got divorced.

\section{Timeless background variables}

6. Head's education, a proxy for income stability and a longer time horizon.

7. Race, a proxy for income insecurity, restricted choices, etc.

8. Region, a proxy both for availability and cost of housing, and for differential rates of increase in housing prices.

9. Size of largest city in the area, a proxy for job opportunities, cost of housing, differential inflation, and number of available alternatives.

10. Age of head, as a proxy for likely length of residence and job tenure and probably having made the necessary adjustments, or else for the fact that older people face declining space needs, but better financial ability to avoid reducing space.

11. Decile of family income/needs the year before the move as an indicator of affluence and ability to satisfy changing housing needs, or to use more of any income increase to upgrade housing.

Changes during the year of the move

12. Change in home ownership, because our conversion of rent and rentequivalents to house values is imperfect, and because owners spend more on housing than renters. We use four groups: became an owner, stayed an owner, stayed a non-owner, ceased owning.

13. Change in family composition, a complex classification ranging from no change in family members to new families created by splitoffs or marriages of women.

14. Number who moved into the household during the year.

15. Number who moved out of the household during the year.

16. Change in income in the year after the move, a proxy for moving in anticipation of the increase, or moving to a better job.

\section{Analysis of change in number of rooms}

Fig. 1 shows the results for change in number of rooms for the 8,120 family-moves between 1978 and 1983. Overall, there was an average decrease 


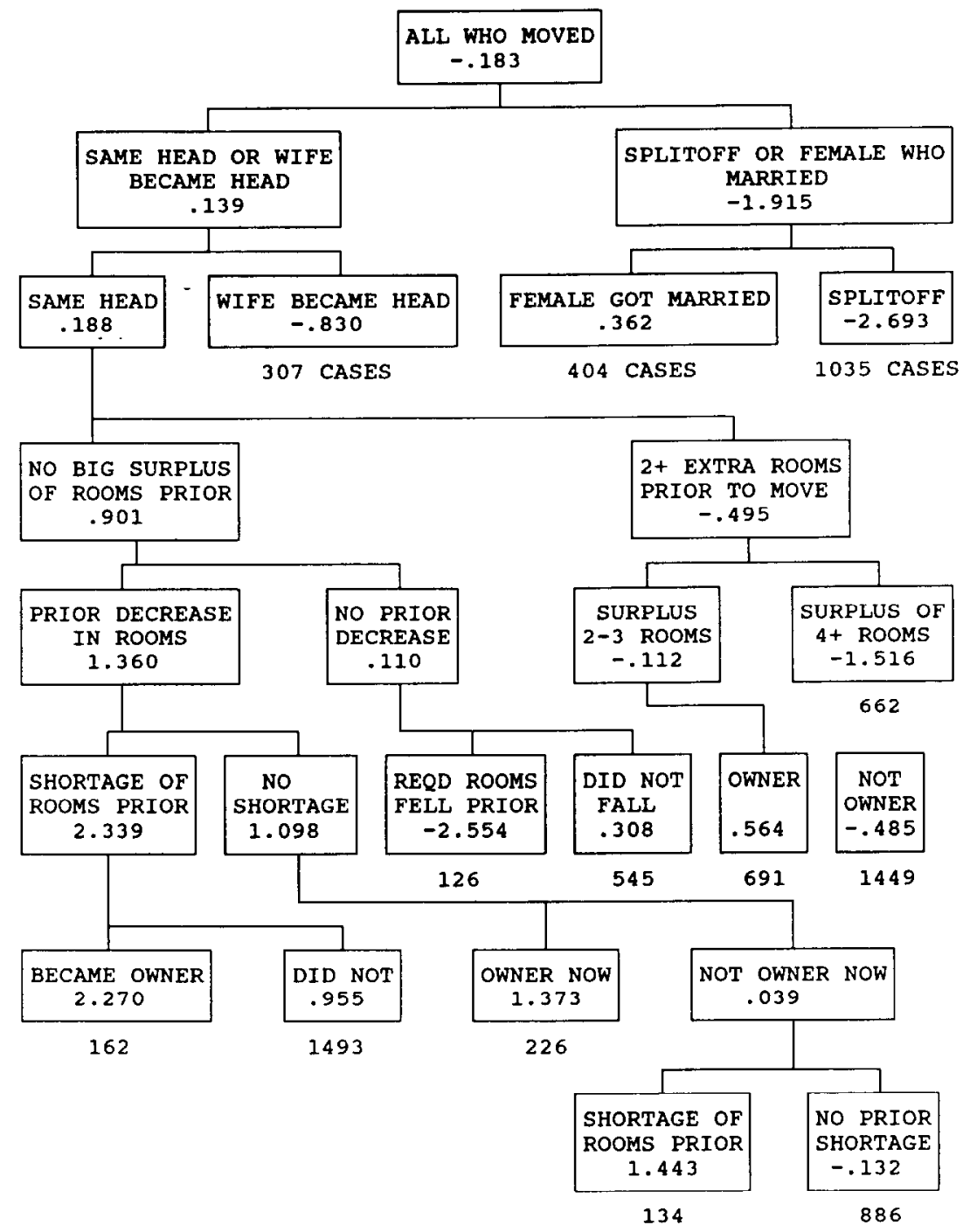

Fig. 1. Change in number of rooms, for 8,120 who moved between 1978 and 1983 (13 final groups account for $32 \%$ of the variance).

in 0.18 room, because most of the families with new heads are splitoffs, with an average decrease of 1.92 rooms leaving the rest with an average increase of 0.14 rooms. That remaining group is then divided into families with the same head and those where a prior wife became head, by divorce or death of the husband. After forcing those first two splits, the program itself decides on 
the rest in such a way as to maximize the explained variance. The group of changed heads is divided into single women who got married (with an increase in rooms of 0.38 ) and the splitoffs who formed new households, with an average decrease of 2.69 rooms.

Turning to the families with no change in head, the dominant factor accounting for change in rooms was the initial surplus or shortage of rooms relative to an estimate of 'required rooms' based on the assumption that children could share bedrooms till age 18 if they were of the same gender, and until they were 10 if they were of different genders.

The only other factors important enough to cause a split in any of the groups were ownership or becoming an owner. It is generally known that people will consume more housing when they own than when they rent, for a variety of reasons. Apparently such effects dominate those of changes in income, though it may have been income changes that led to becoming an owner.

What did not matter is more impressive and unsettling, particularly the absence of effects of income level or income change, or age. Life course theory might well argue for early increases, even in anticipation of later needs, and decreases late in life to avoid the burden of maintenance. Consumer economics would assume that income changes lead to upgrading, including more rooms as well as more dollars per room.

What we appear to have is family changes and prior failures to adjust to them as indicated by initial shortages or surpluses of rooms, plus a decision to become or remain an owner, dominating changes in number of rooms. The 12 splits form 13 final groups which account for $32 \%$ of the overall variance in the change in number of rooms. An examination of the remaining potential within the final groups for accounting for residual variance with prior income trends shows only one group where it could have accounted for as much as half of $1 \%$ of the original variance, and for that group the initial surplus/shortage of rooms could account for twice as much. Indeed for only two final groups could prior income trend account for more of the remainder than more detail on initial surplus/shortage of rooms: one is a small group of 162 who became homeowners at the time of the move, and who had no big shortage or surplus of rooms before the move, but a prior decrease in number of rooms. Hence, upgrading may take place in response to an income increase mostly when it also involves becoming an owner or suffering a previous shortage of space (rooms). The other group is 226 owners. Both groups had large average increases in number of rooms.

Economic effects are clearly present, but just as clearly dominated by other considerations in most moves. A realtor looking for customers would do well to focus less on people being promoted than those getting married, divorced, having children, losing children, or on children leaving home. 


\section{Analysis of change in value - Economic upgrading}

But perhaps the upgrading is largely in the value per room, so we turn to an analysis of the change in house value. We divide the change by the mean of the before and after values, to put it in symmetric relative terms and to avoid scale effects and resulting spurious correlations.

Of the 8,120 moves during the five year period, $16 \%$ involved a change in the head at the time of the move (including a wife who became a head). Many 'moves' are kids leaving home. Remember, that when a divorce occurs there may be two moves, and there is usually at least one. And since we are interested in the five year prior trend in income, we need to focus on families with the same head during that period. Some $61 \%$ of moves are by households without the same head for the five years prior to and during the move. So for the rest of the analysis, we restrict ourselves to moves where the family head was unchanged during the move and the prior period of estimating income trend. If we take the remaining 2,887 cases of moves, we can force the first split to separate out the cases where there is a change in the wife (man got divorced, or married, or widowed or some combination of those). (See group 3 in fig. 2.) The average change in housing is downward for that group, but with a substantial effect of prior income change in the expected direction, implying that there were larger reductions in housing when the prior income trend had been worse.

We did this analysis in three ways, the first treating the relative change in house value as a single dependent variable with the prior relative income trend as one of the explanatory characteristics, and the second and third in covariance searches, looking for groups where two simple regressions of change in house value on prior trend in income accounted for the most variance, with and without allowing the levels of the subgroups to matter. The analysis of mean change in house value used prior income only for upper income owners not near retirement age, or lower income renters with a prior surplus of rooms and not in one of the largest metro areas.

We present details only of the two covariance analyses. Actually the regression or first covariance search is dominated by differences in the mean of the dependent variable (change in house value), so 12 splits, forming 13 final groups accounted for the same total amount of variance as the means analysis, even though the covariance analysis took account of income change in every group, while the other never took account of it. In both cases, since these were all families with the same head, the divisions were mostly not on initial shortage or surplus of rooms, but becoming an owner or a renter, or having changes in family size or marital status. Fig. 2 presents the covariance search analysis, with each box showing the mean relative change in house value, the regression slope of value change on income change (a kind of income elasticity) and the size of the correlation coefficient. 


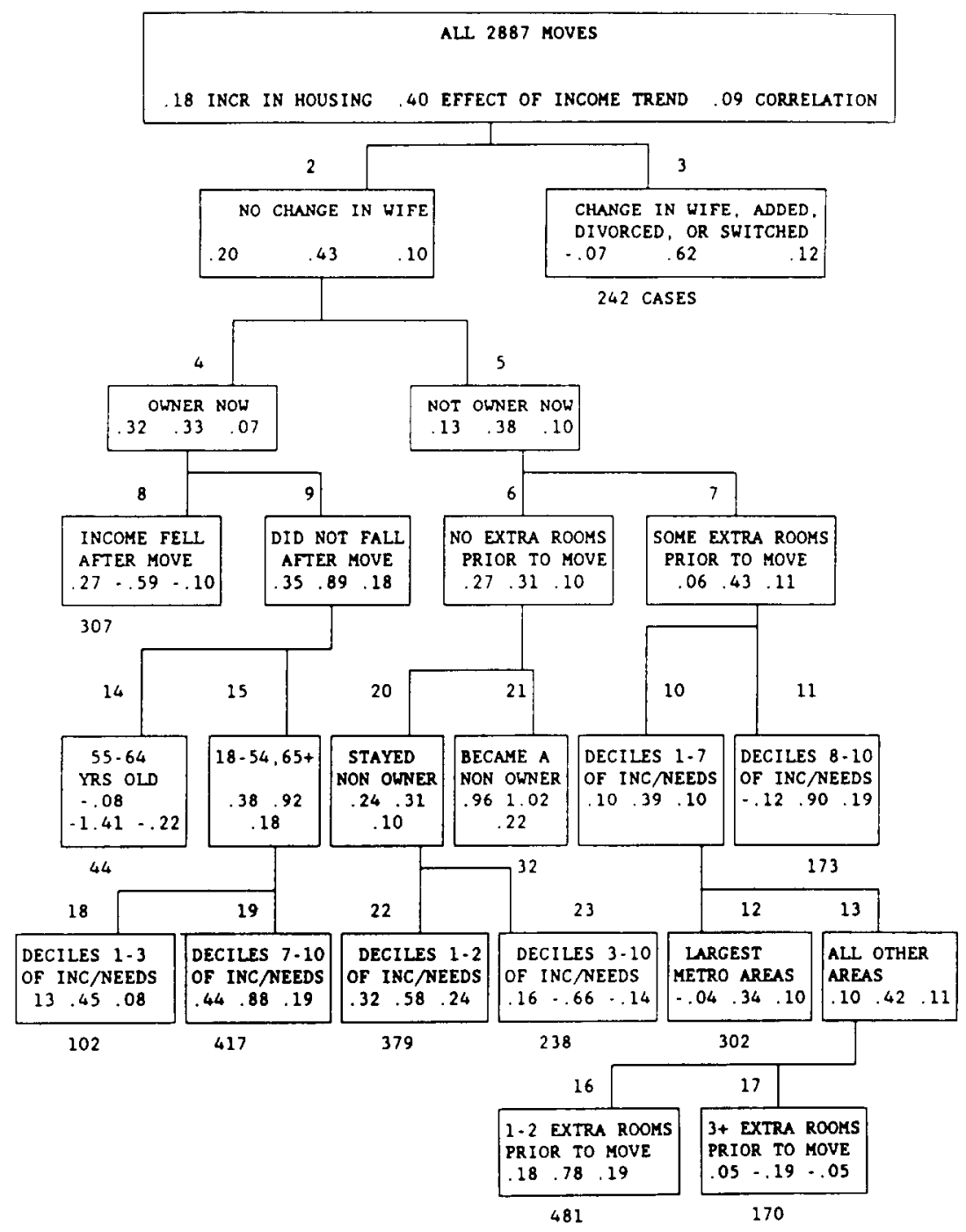

Fig. 2. Search for different effects of prior income trend on upgrading of housing conditional on having moved (regression option, for 2,887 moves 1978-1983 and with no change in family head in prior 5 years, 11 final groups account for $10 \%$ of the variance, most of it from differences in the mean relative change in housing).

Since the explanation of variance in fig. 2 is dominated by means (level of dependent variable) rather than slopes (size of income-change effect), we look first at the mean changes which vary from a $44 \%$ increase for upper income owners not near retirement age whose income did not fall after the move 
(group 19), to $-12 \%$ for upper income non-owners with extra rooms prior to the move (group 11), many of whom probably sold a house and now rent.

Turning to the income effects, we notice first that many of the splits set aside groups where things other than the past income trend are affecting the housing change: ownership, a (probably expected) income fall after the move, a retircment transition for those 55-64 years old, or ability to upgrade as indicated by immediately prior income/needs. But income 'elasticities' never get very large. We move on quickly because the main purpose of fig. 2 was to compare it with the next fig. 3 which focuses on differences in income effects.

The new slopes-only option, searching for movers with different effects of prior income on upgrading

The new option in the SEARCH program eliminates the domination of the splitting by changes in the mean house value, by recentering each subgroup around its own mean changes in house value and income. Fig. 3 deals again only with the 2,887 moves where the head had not changed for five years, applies the identical predictors and strategy, but uses the new slopes-only option.

After the forced splitting of those with a change in wife, the automatic search for groups with different income effects first set aside group 4, those around retirement age, where the prior income trend is largely meaningless as an indicator of future ability to afford housing, and where the correlation is substantially negative. Next we segregate the top 8 deciles of the income/ needs distribution (group 7) with a smaller effect of prior income trend, implying that level of affluence affects the relative upgrading of housing when income changes! The lower two deciles were affected by non-linearity in the effect of prior income trend, and by income change after the move, expectation of which apparently enhanced the effect of prior income changes. Among the rest, those with other changes in the family during the move (group 9) are set aside, with a negative effect of prior income trend. Perhaps children whose earnings had been rising split when the family moved, reducing both the family income and the need for space.

The remaining splits continue to illustrate beautifully the way in which one can sort out some reasonably normal unconstrained groups whose response to prior income trends might be considered a good estimate of the income elasticity of the demand for housing.

Continuing with the 'mainstream' group 8, we set aside:

(i) those 75 or older (Group 10);

(ii) those with a prior shortage of rooms (group 12);

(iii) those in deciles 3-7 of income/needs, presumably less able to respond to income changes because of lack of borrowing power (group 14); 


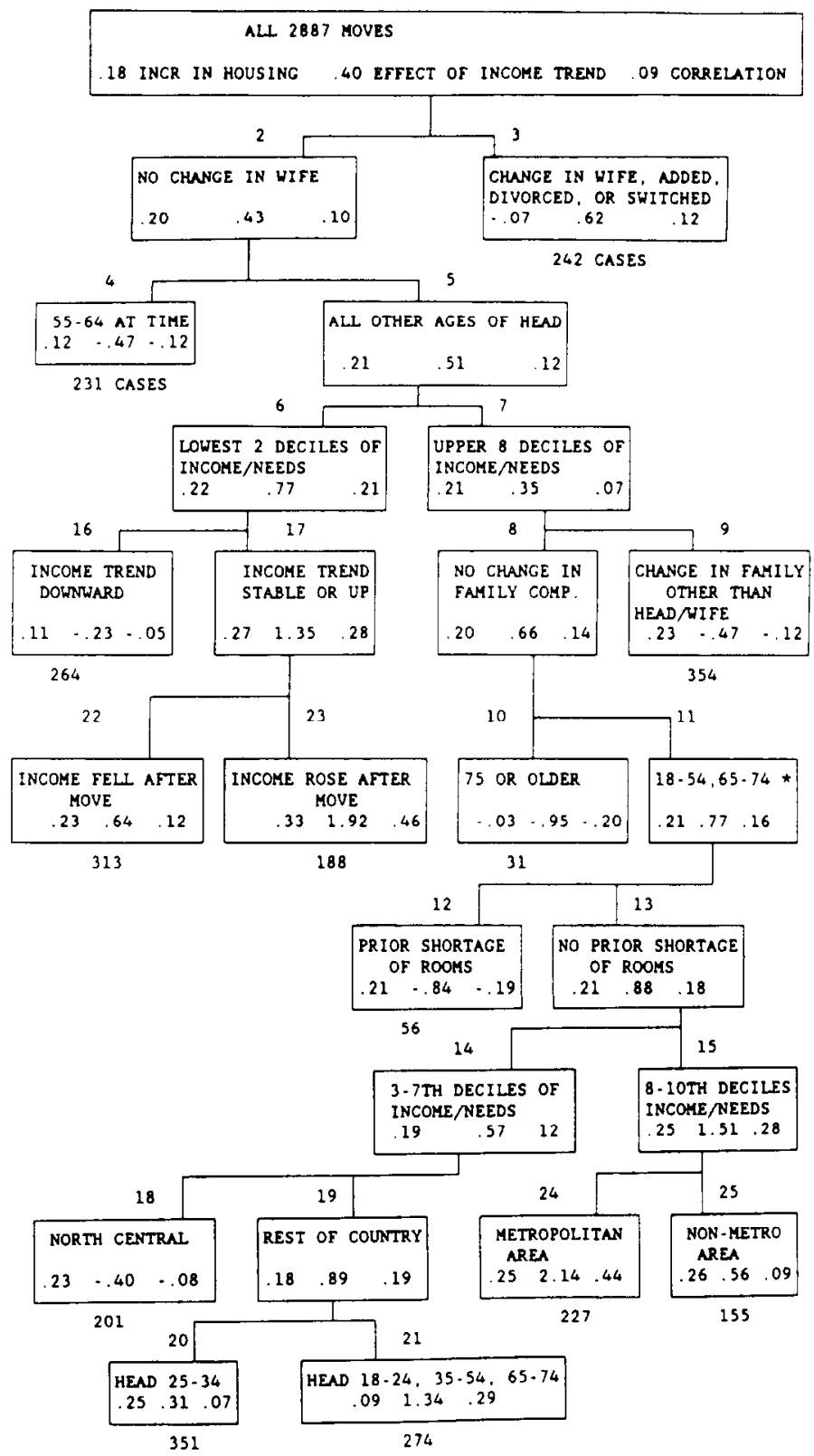

Fig. 3. Search for different effects of prior income trend on upgrading of housing conditional on having moved (slopes only option, for 2,887 moves 1978-1983 and with no change in family head in prior 5 years, 13 final groups account for $4 \%$ of the variance). 
(iv) those in deciles 3-7 of income/needs but also in the North Central, an area of rapidly escalating house prices (group 18).

Each time we eliminate one of these special groups, the estimated effect of income trend on housing upgrading becomes larger for the others, and the correlation higher. What, then, is the effect of income trends on housing upgrading? Only a simulation model which specified which subgroups received the income increases could provide a reasonable estimate. If one wanted the base, unconstrained unstimulated estimate, would it be the 1.92 of group 23, or the 0.89 of group 19 , or the 2.14 of group 24 , or the 0.56 of group 25 ?

Remember that the 'income elasticity' we measure is the effect of the prior five year annual trend in dollar family income relative to the five year mean, on the change in house value or rent relative to the mean of the two values, a kind of arc elasticity not dominated by extreme cases, and symmetrical in treating increases and decreases. Without using such a measure, the average of the effects of increases and decreases would be biased upwards by using the (larger) base for decreases.

The overall picture is one of a genuine effect of income trend on housing upgrading among movers not constrained by other things, or not propelled into moving by other events. But if we look at the total 'housing market' we find that an economic model predicting the demand for housing on the basis of prior family income trends, would be predicting only a small fraction of the buyers. A simulation model which incorporated changes in family composition, retirements, accumulated shortages of rooms, and areas of temporary income changes or rapidly changing housing prices (as in the metropolitan areas), would do better, since these other events do not randomize out across time or space.

Full modeling would of course also have to deal with the decision to move in the first place, and the decision to become an owner, but it is likely that those decisions are even more dominated by considerations other than prior income trends, things like marriage, divorce, arrival or departure of children or other relatives.

To what extent are the things other than income trends that affect upgrading of housing randomly distributed noise that averages out, or at least have random changes over time in their effects on the aggregate demand? There are some large demographic changes related to the baby boom and bust that should affect aggregate trends, and there are effects of good or bad times on the speed with which children leave home to set up their own households. And national monetary policy can certainly change the apparent price of houses by altering interest rates.

Finally, even though housing changes for many are dominated by many things other than prior trends in family income, could we believe that the 
clear effects we observe in the unconstrained cases also apply to others, being simply masked by other things, so that trends in family income would have those same effects on all movers, whatever else mattered? It seems doubtful in the case of the main exceptions - those with changes in the husband or wife, when there is someone leaving home or a divorce.

We repeated the analysis using as the covariate not the prior trend in family income, but the prior trend in family income/needs, a better measure of ability to pay. The results are similar. And the differences between the regression option and the slopes-only focus on different income effects are similar. Hence we do not present the trees.

\section{Discussion}

Since our analysis is conditional on a prior decision to move which we have not analyzed, the main power of economic factors might appear in that decision. Prior analyses by Jack Goodman and Sandra Newman show that initial economic disequilibrium is important. (Their disequilibrium relates actual to 'expected' house value.)

But there remain wide differences in the impact of prior income change, or prior change in income/needs, on the change in house value produced by the move. Income seems to have the most effect when it combined with other incentives like the need for space or the desire to own one's own house, but free of distortions or other pressures like family changes or initial shortages so we can measure it.

Given the wide differences in estimatcd income clasticities among different groups, attempts to use multiple regression to estimate a single such elasticity would appear unwise. Only if the different groups had different average changes in house value, but similar regression slopes, would such pooling be appropriate. Economic theory lives, and there are people at the margin with freedom to make choices, who respond as the theory predicts. But testing economic theories with survey data requires searching out the subgroups where it applies, and realizing that the strength of the response may differ widely. The aggregate response of income changes to housing demand is thus a complex result of differential income changes among different groups with different responses. Microanalytic modeling is essential, and data analysis searching for different subgroup responses also appears essential.

A final warning: Regression slopes are notoriously unstable, and the weights used to keep the PSID representative introduce heterogeneity into already high-variance data. Rerunning the SEARCH slopes-only program on unweighted data gives sometimes dramatically different subgroups and different estimated income-trend effects within the same subgroups. We are still working on this. In the meantime, large minimum group sizes may be suggested, as well as care about outliers. 


\section{References}

Apgar, William and Henry Pollakowski, 1986, Housing mobility and choice (Joint Center for Housing Studies, Harvard, Cambridge, MA) June.

Brown, James N. and Harvey S. Rosen, 1982, On the estimation of structural hedonic price models, Econometrica 50, May, 765-768.

Leeuw, Frank de, 1971, The demand for housing: A review of cross section evidence, Review of Economics and Statistics 53, Feb., 1-10.

Downs, Anthony and Katharine Bradbury, 1981, Do housing allowances work? (Brookings, Washington, DC).

Friedman, Joseph and Dan Weinberg, 1982, The economics of housing vouchers (Academic Press, San Diego, CA).

Goodman, Jack, 1976, Housing consumption equilibrium and local residential mobility, Environment and Planning B, 855-874.

Hanushek, E.A. and J.M. Quigley, 1978, An explicit model of intrametropolitan mobility, Land Economics 54, 411-429.

Henderson, J. Vernon, 1985, Economic theory and the cities (Academic Press, Orlando, FL).

Henderson, J.V. and Y.M. Ioannides, 1983, A model of housing tenure choice, American Economic Review 73, 98-113.

Henderson, J.V. and Y.M. Ioannides, 1986, Tenure choice and the demand for housing, Economica 53, 231-246.

Henderson, J.V. and Y.M. Ioannides, 1987. Consumption vs investment demand, Journal of Urban Economics 21, 228-241.

Henderson, J.V. and Y.M. Ioannides, 1989, Dynamic aspects of consumer decisions in housing markets, Journal of Urban Economics 26, 212-230.

Ioannides, Y.M., 1987, Residential mobility and housing tenure choice, Regional Science and Urban Economics 17, 265-287.

Ioannides, Y.M., 1989, Housing other real estate, and wealth portfolios, Regional Science and Urban Economics 19, 259-280.

Mayo, Stephen K., 1981, Theory and estimation in the economics of housing demand, Journal of Urban Economics 10, July, 95-116.

Murray, Michael P., 1983, Mythical demands and mythical supplies for proper estimation of Rosen's hedonic price model, Journal of Urban Economics 14, Nov., 326-337.

Newman, Sandra J. and Greg J. Duncan, 1978, Residential problems, dissatisfaction, and mobility, in: Greg Duncan and James Morgan, eds., Five thousand American families: Patterns of Economic Progress 6 (Institute for Social Research, Ann Arbor, MI).

Newman, Sandra J. and James D. Reschovsky, 1987, Federal policy and the mobility of older homeowners, Journal of Policy Analysis and Management 6, 402-416.

Quigley, John M., 1979, What have we learned about urban housing markets?. in: Peter Mieszkowski and Mahlon Straszheim, eds., Current issues in urban economics (The Johns Hopkins Press, Baltimore, MD).

Rothenberg, Jerome, 1983, Housing investment, housing consumption and tenure choice, in: Ronald E. Grieson, ed., The urban economy and housing (Heath, Lexington Books, Lexington, $\mathbf{M} \Lambda$ ).

Smith, Lawrence B., Kenneth T. Rosen and George Fallis, 1988, Recent developments in economic models of housing markets, Journal of Economic Literature 26, Mar., 29-64.

White, Michael, 1987, American neighborhoods and residential differentiation (Russel Sage Foundation, New York). 